\title{
Incidence and risk factors for sustained hepatic function toxicity 6 months after radioembolization: analysis of the radiation-emitting sir-spheres in non-resectable liver tumor (RESIN) registry
}

\author{
Daniel Brown ${ }^{1}$, Henry Krebs ${ }^{2}$, Jayson Brower ${ }^{3}$, Ryan O’Hara ${ }^{4}$, Eric Wang ${ }^{5}$, Kirubahara Vaheesan ${ }^{6}$, \\ Liping Du ${ }^{1}$, Lea Matsuoka ${ }^{1}$, Donna D'Souza ${ }^{7}$, Daniel Y. Sze ${ }^{8}$, Jafar Golzarian ${ }^{7}$, Ripal Gandhi ${ }^{9}$, \\ Andrew Kennedy ${ }^{10}$
}

${ }^{1}$ Vanderbilt University Medical Center, Nashville, TN, USA; ${ }^{2}$ Cancer Treatment Centers of America, Newnan, GA, USA; ${ }^{3}$ Providence Sacred Heart Medical Center, Spokane, WA, USA; ${ }^{4}$ University of Utah, Salt Lake City, UT, USA; ${ }^{5}$ Carolinas Medical Center, Charlotte, NC, USA; ${ }^{6}$ Saint Louis University, St. Louis, MO, USA; ${ }^{7}$ University of Minnesota, Minneapolis, MN, USA; ${ }^{8}$ Stanford University, Palo Alto, CA, USA; ${ }^{9}$ Miami Cardiac and Vascular Institute, Miami, FL, USA; ${ }^{10}$ Sarah Cannon Research Institute, Nashville, TN, USA

Contributions: (I) Conception and design: D Brown; (II) Administrative support: None; (III) Provision of study materials or patients: D Brown, H Krebs, J Brower, R O’Hara, E Wang, K Vaheesan, D D’Souza, DY Sze, J Golzarian, R Gandhi; (IV) Collection and assembly of data: D Brown, L Du; (V) Data analysis and interpretation: D Brown, L Matsuoka, D D’Souza, DY Sze, A Kennedy; (VI) Manuscript writing: All authors; (VII) Final approval: All authors.

Correspondence to: Daniel Brown, MD. 1161 21st Ave S, CCC-1118 Medical Center North, Nashville, TN 37232, USA.

Email: daniel.b.brown@vumc.org.

Background: To quantify rates and risk factors for toxicity after hepatic radioembolization using resin yttrium-90 microspheres.

Methods: Radiation-Emitting SIR-Spheres in Non-resectable liver tumor (RESIN) registry enrollees were reviewed with 614 patients included. Mean patient age was $63.1 \pm 12.5$ years. The majority of patients were male $(n=375,61 \%)$ and white $(n=490,80 \%)$. Common tumor types were hepatocellular $(n=197,32 \%)$, colorectal $(n=187,30 \%)$ and neuroendocrine $(n=56,9 \%)$. Hepatotoxicity was measured using the Common Terminology Criteria for Adverse Events (CTCAE v 5). Potential risk factors for hepatotoxicity were tested using the Kruskal-Wallis or Pearson Chi-squared tests, and multivariate linear regressions.

Results: At 6 months, 115 patients (18.7\%) died ( $n=91,14.8 \%)$, entered hospice $(n=20,3.3 \%)$ or sought treatment elsewhere $(n=4,4 \%)$. Seven $(1.1 \%)$ deaths were from liver decompensation. Grade 3 toxicity rates were: bilirubin $(n=85,13.8 \%)$, albumin $(n=28,4.6 \%)$, ALT $(n=26,4.2 \%)$ and AST $(n=37,6.0 \%)$. For each of these liver function test components, baseline abnormal labs predicted Grade 3 toxicity at followup by Kruskal-Wallis test $(\mathrm{P}<0.001)$ and linear regression ( $\mathrm{ll} \mathrm{P}<0.03)$. Other significant factors predicting toxicity at regression included elevated Body-Mass Index (albumin $\mathrm{P}=0.0056$ ), whole liver treatment (bilirubin $\mathrm{P}=0.046$ ), and lower tumor volume (ALT and INR, $\mathrm{P}<0.035$ for both).

Conclusions: Baseline liver function abnormalities prior to radioembolization is the strongest predictor of post-treatment Grade 3 toxicity with rates as high as $13.8 \%$. Toxicity rates for specific lab values are affected by large volume treatments especially with low tumor volumes.

Keywords: Radioembolization; brachytherapy; hepatocellular carcinoma (HCC); colorectal carcinoma; liver metastases

Submitted Sep 09, 2020. Accepted for publication Dec 07, 2020.

doi: 10.21037/jgo-20-346

View this article at: http://dx.doi.org/10.21037/jgo-20-346 


\section{Introduction}

Transarterial radioembolization (TARE) is a component of many interventional oncology practices (1-3). Beyond, hepatocellular carcinoma (HCC) and neuroendocrine tumor, integration of radioembolization for other tumors into treatment guidelines has been challenging (4-7). A contributing factor to slow incorporation of TARE has been the failure to reach primary endpoints in all recent randomized prospective trials to treat colorectal carcinoma and HCC $(8,9)$. With development of newer drugs and modalities to treat hepatic dominant tumors, combining TARE with other targeted therapies or following targeted external beam radiotherapy will need to be assessed with limited existing outcomes and toxicity data. Greater use in practice will require larger data sets, including expected toxicity profiles (2,10-14).

For patients with liver-dominant, but not isolated disease, integrating arterial treatment with other systemic, biologic, or immune therapies could result in improved patient outcomes, resulting in greater utilization of intraarterial therapy $(2,15)$. Patients with cirrhosis-related HCC or undergoing treatment with hepatotoxic drugs such as oxaliplatin or irinotecan may be at different risks of hepatotoxicity with TARE than other patients. However, a recent publication suggested toxicity development beyond 3 months in neuroendocrine tumors, a disease entity without either of the above characteristics (RECH) (16). An updated understanding of expected radioembolization-related hepatic toxicity will facilitate future combination trials. The resulting information could affect patient selection, dosimetry, and selection of potential agents to study in combination therapy.

The Radiation-Emitting SIR-spheres In Non-resectable liver tumor (RESIN) registry (NCT02685631) is a prospective observational study collecting data regarding dosimetry, response and toxicity for tumors treated with ceramic radioembolization emitting microspheres (Sirtex, Boston, MA, USA). Study sites include the spectrum of interventional radiology practices from academic centers to private practice groups, allowing a real-world evidence of device utilization in the United States. The primary purpose of the current review was to review data to quantify hepatic toxicity incidence 6 months after therapy with radioembolization and identify demographic and clinical factors which increased risk of significant toxicity of liver function. We present the study in accordance with the STROBE reporting checklist (available at http://dx.doi. org/10.21037/jgo-20-346).

\section{Methods}

\section{Registry structure}

The RESIN registry is an observational database. This study (GI 1523) was approved by the institutional review board at Vanderbilt University Medical Center (IRB \#150407) and at the other sites. Informed consent was obtained from all patients at each center. The study was performed in keeping with the Declaration of Helsinki (as revised in 2013). As a real-world data collection, physicians at each site assessed patients for appropriateness for treatment, prescribed activity and ordered follow-up labs and imaging per local practice. Inclusion criteria were based on local decision-making and operator decision that TARE was an appropriate therapy. Patients had to be 18 years old or older and had to be capable of providing informed consent. No surrogate consent was allowed. Specific tumor sizes and laboratory thresholds were not used to determine eligibility in this data collection. At the time of data evaluation (March, 2020), 614 patients had demographic, prescription and treatment data entered along with 6-month imaging and/or laboratory follow-up data. This review tracks outcomes at 6 months after initial TARE treatment. Disease types with an incidence of less than 5 patients were designated as "other" and grouped together. Patients who received systemic therapy were divided into groups receiving one, two, or three or more lines of therapy. Patients were enrolled on the date of first radioembolization. The Society of Interventional Radiology Quality Improvement Guidelines were used for terminology (17).

\section{Demographics}

Baseline patient factors by tumor type are outlined in Table 1. Median and mean age was 65 and $63.1 \pm 12.5$ years (range, 20-93 years). Three hundred seventy-five (61.1\%) male, 238 female $(38.8 \%)$ and 1 non-binary $(0.2 \%)$ patients were treated. HCC $(\mathrm{n}=197)$, colorectal carcinoma $(n=187)$, and neuroendocrine tumor $(n=56)$ were the most common diagnoses. There were significant differences between tumor types in patient age and gender. The oldest patient group was cholangiocarcinoma (median 70; IQR 63.2-74.8). HCC had the most male patients for any tumor type $(78 \%)$. Five hundred forty three patients $(91 \%)$ were ECOG $0(274,46.0 \%)$ or 1 (269, 45.2\%). Seven ECOG 3-4 


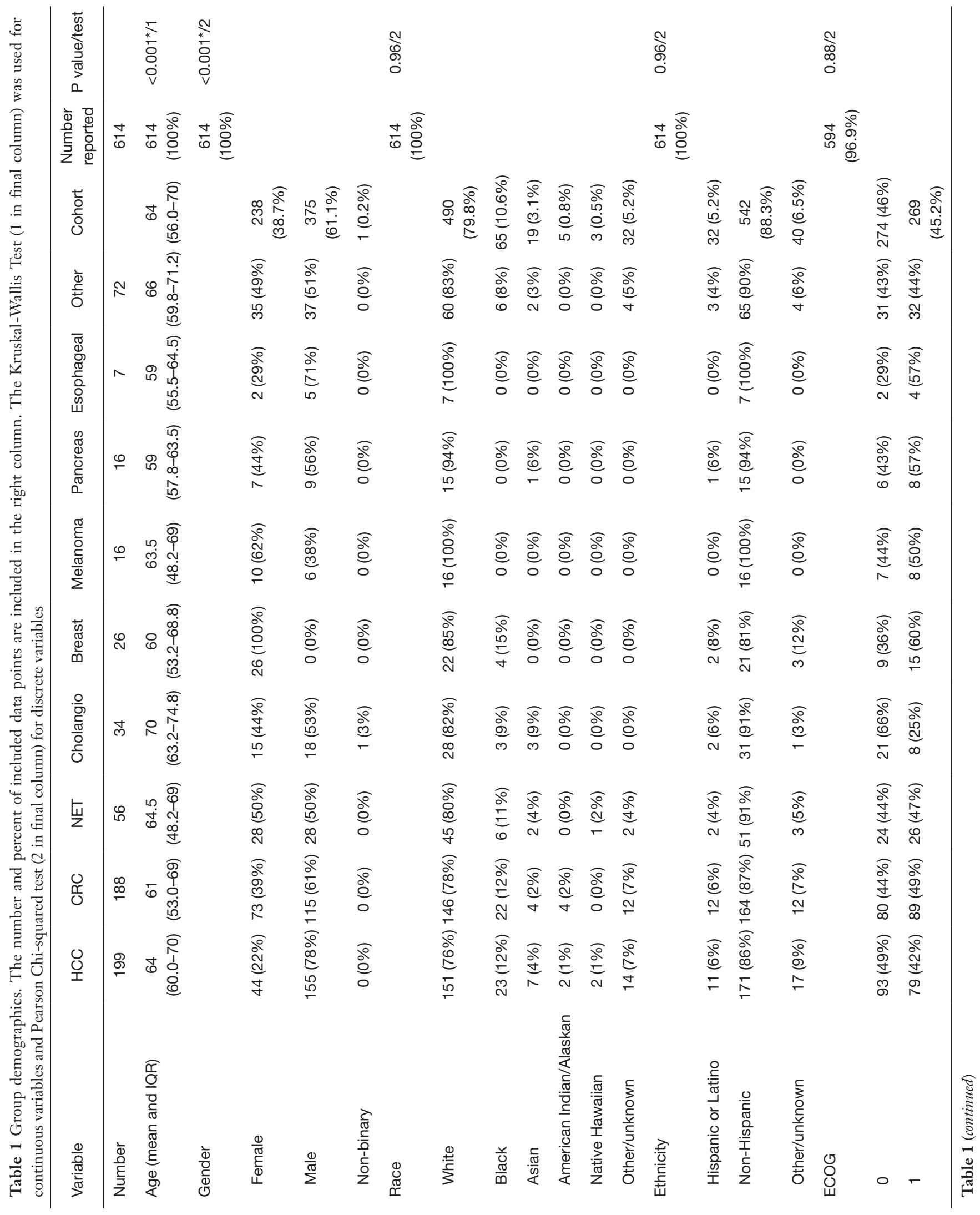




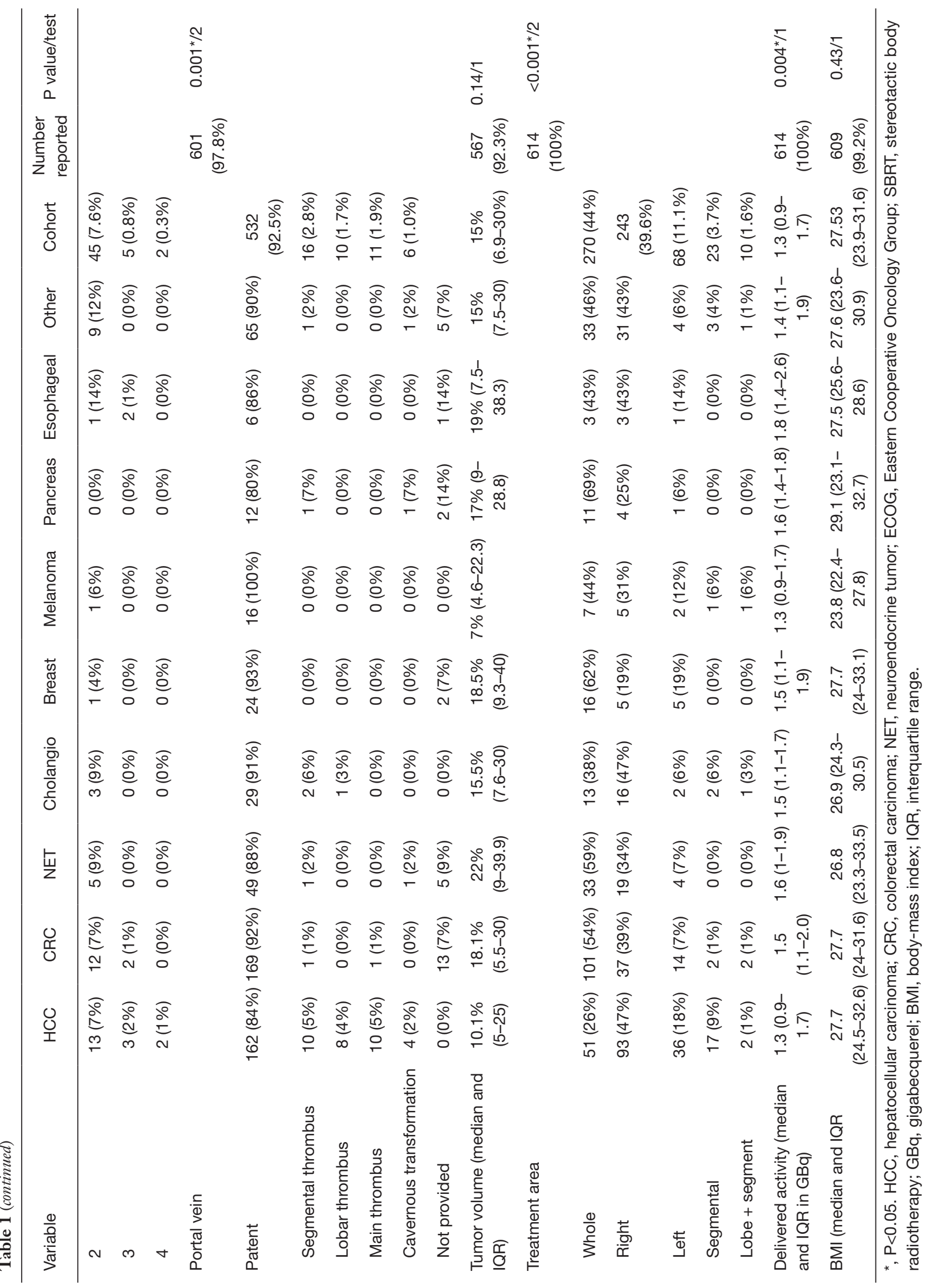


Table 2 Treatments prior to radioembolization by tumor type

\begin{tabular}{lcccccccc}
\hline Pathology & Total (N patients) & Surgery & Chemo 1 line & Chemo 2 lines & Chemo 3+ lines & Ablation & SBRT & Arterial \\
\hline Hepatocellular & 197 & $8,4.1 \%$ & $28,14.2 \%$ & $20,10.2 \%$ & $8,4.1 \%$ & $24,12.2 \%$ & $2,1.0 \%$ & $50,25.4 \%$ \\
Colorectal & 187 & $29,15.5 \%$ & $35,18.7 \%$ & $43,23.0 \%$ & $61,32.6 \%$ & $26,13.9 \%$ & $12,6.4 \%$ & $14,7.5 \%$ \\
Neuroendocrine & 56 & $8,14.3 \%$ & $20,35.7 \%$ & $9,16.1 \%$ & $14,25 \%$ & $4,7.1 \%$ & $3,5.4 \%$ & $9,16.1 \%$ \\
Cholangiocarcinoma & 35 & $3,8.6 \%$ & $11,31.4 \%$ & $6,17.1 \%$ & $5,14.3 \%$ & $2,5.7 \%$ & $4,11.4 \%$ & $4,11.4 \%$ \\
Breast & 27 & $1,3.7 \%$ & $1,3.7 \%$ & $3,11.1 \%$ & $15,55.6 \%$ & $2,7.4 \%$ & $1,3.7 \%$ & $3,11.1 \%$ \\
Melanoma & 16 & $0,0 \%$ & $6,37.5 \%$ & $4,25 \%$ & $2,12.5 \%$ & $1,6.3 \%$ & $1,6.3 \%$ & $1,6.3 \%$ \\
Pancreatic & 16 & $2,12.5 \%$ & $4,25 \%$ & $4,25 \%$ & $4,25 \%$ & $0,0 \%$ & $2,12.5 \%$ & $1,6.3 \%$ \\
Esophageal & 7 & $0,0 \%$ & $1,14.3 \%$ & $2,28.6 \%$ & $4,57.1 \%$ & $0,0 \%$ & $1,14.3 \%$ & $0,0 \%$ \\
Other & 73 & $8,11.0 \%$ & $20,27.4 \%$ & $17,23.3 \%$ & $27,37 \%$ & $5,6.8 \%$ & $7,9.6 \%$ & $4,5.5 \%$ \\
Total & $614,100.0 \%$ & $59,9.6 \%$ & $126,20.5 \%$ & $108,17.6 \%$ & $140,22.8 \%$ & $64,10.4 \%$, & $27,5.1 \%$ & $86,14.0 \%$ \\
\hline
\end{tabular}

Chemo, systemic therapy; SBRT, stereotactic body radiation to hepatic malignancy; Arterial, previous embolization or chemoembolization.

(1.1\%) patients were treated after clinical assessment. Five of these patients had HCC and 2 had colorectal carcinoma. Portal vein thrombosis was most common in the HCC group. Twenty-eight HCC patients (14\%) had segmental $(n=10 ; 5 \%)$, lobar $(n=8,4 \%)$, or main $(n=10,5 \%)$ portal vein thrombosis. Median and mean delivered activity was 1.4 and $1.5 \pm 0.7$ gigabecquerels $(\mathrm{GBq})$. Investigators used quantitative tools to assess tumor burden in 331 patients $(58 \%)$ and visual assessment in the remainder. Whole-liver treatment was the most common approach, in $270(44 \%)$ of patients. Infusion of a lobe plus an additional segment was the least common approach $(n=10,1.6 \%)$. The median prescribed activity by treatment area was: whole liver: 1.9 GBq (IQR: 1.6-2.2 GBq), right lobe 1.2 GBq (IQR 1-1.5 GBq), left lobe: $0.8 \mathrm{GBq}$ (IQR: 0.6-1 GBq), SEGmental: 0.9 GBq (0.4-1.1 GBq), lobe plus segment: $1.3 \mathrm{Gbq}(1-1.5 \mathrm{GBq})$.

Treatments prior to TARE are outlined by tumor type in Table 2. The most common treatments prior to TARE was systemic therapy $(n=374,60.9 \%)$. In this review, systemic therapy accounts for any treatment prescribed by a medical oncologist including chemo-, biologic and immunotherapies. For patients who received systemic therapy, the average number of treatment lines prior to radioembolization was 2.3 . One hundred forty (22.8\%) patients received three or more lines of systemic therapy, including $61(32.6 \%)$ colorectal cancer and 15 (55.6\%) breast cancer patients. Fifty-five (10\%) patients underwent resection, most commonly for colorectal carcinoma $(\mathrm{n}=29,15.5 \%)$ and neuroendocrine tumor $(\mathrm{n}=8,14.3 \%)$.
Regarding locoregional therapies, arterial embolization was the most common. Eighty-five patients (14\%) underwent chemoembolization or embolization, most commonly in patients with HCC $(\mathrm{n}=50,25.4 \%)$, and neuroendocrine tumor $(\mathrm{n}=9,16.1 \%)$.

\section{Follow-up}

Lab and imaging follow-up were performed per institutional preferences with data collected at 6-month intervals. Quantifiable toxicities of liver function were assessed using serum bilirubin, albumin, alanine aminotransferase (ALT), aspartate aminotransferase (AST) and international normalized ratio (INR) with toxicity defined using common terminology criteria for adverse events (CTCAE) version 5. Additionally, absolute neutrophil count was assessed at 6 months. Patients who left the study were censored at the date of removal. The presence and grading of baseline lab abnormalities was defined using values previously used in CTCAE v4 including bilirubin $>1.8 \mathrm{mg} / \mathrm{dL} \quad(\mathrm{n}=89$, $14.5 \%)$, albumin $<3 \mathrm{~g} / \mathrm{dL}(\mathrm{n}=391,63.7 \%)$, ALT $>450 \mathrm{U} / \mathrm{L}$ $(\mathrm{n}=174,28.3 \%)$, AST $>450 \mathrm{U} / \mathrm{L}(\mathrm{n}=200,32.6 \%)$, and INR $>1.8(n=19,3.1)$ for patients not on anticoagulation. Additional treatments in the 6-month window after TARE were tracked. Final toxicity assessment was performed at 6 months \pm 2 weeks or when censored. Toxicities were calculated using CTCAE v5. Sustained toxicity was defined as Grade 3 or greater toxicity presence at 6 months. Imaging response at 6 months was determined with response criteria in solid tumors (RECIST) or modified RECIST based on 
baseline enhancement characteristics at 6 months \pm 2 weeks or when censored. Objective response was defined as the sum of complete and partial response. Disease control was defined as objective response plus stable disease.

\section{Statistical analysis}

Demographic factors were assessed separately for association with clinical toxicity by grade using the Kruskal-Wallis Test for continuous variables and Pearson Chi-squared test for discrete variables. Multivariable linear regressions were performed for the different post-treatment liver functions to evaluate contributing baseline factors for each different measure of hepatic function to significant toxicity. Finally, for the most common tumor types, multivariable linear

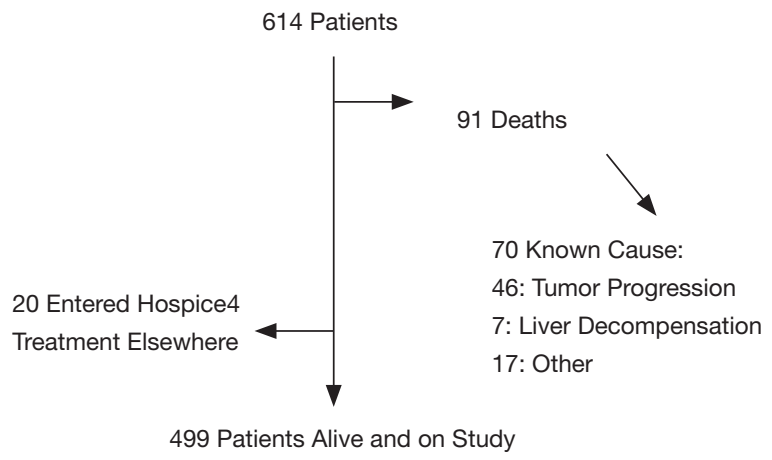

Figure 1 Flow diagram of study participants at 6 months. regression was performed to identify specific baseline factors by pathologic entity. For all analyses, a $\mathrm{P}$ value of $<0.05$ was considered statistically significant. Calculations were performed using R Version 3.6.2 (Vienna, Austria).

\section{Results}

\section{Drop-out}

One hundred fifteen patients (18.7\%) patients dropped off the study at a mean of $112 \pm 36$ days (Figure 1). Ninetyone (79\% of the drop-out group) patients died, 20 (17\%) entered hospice and four (4\%) sought treatment elsewhere. The cause of death was documented in $70(77 \%)$ patients of the 91 who expired. In this subgroup, 46 patients (66\%) died from tumor progression, and 7 (10\%) died from liver decompensation without evidence of tumor progression. The remaining patients died of other causes. The overall liver decompensation rate was $7 / 115$ (6.1\%) for all patients dropping off the study and was $7 / 614(1.1 \%)$ for the entire cohort.

\section{Additional treatments}

Table 3 reviews additional treatments that were given in the 6 months after TARE. One-third of patients (205/614, $33.4 \%$ ) had any type of additional treatment. Chemotherapy was the most common treatment, given to 129 patients (21\%) of the group. Twenty-six of the 45 (58\%) patients with colorectal cancer received $3^{\text {rd }}$ line therapy or beyond. Arterial therapy was used in $15 \%$ of patients with HCC, but

Table 3 Treatments in the first 6 months after radioembolization

\begin{tabular}{lcccccc}
\hline Pathology & Total (N patients) & Surgery & Chemo & Ablation & SBRT & Arterial \\
\hline Hepatocellular & $86 / 197(44 \%)$ & $7(3.6 \%)$ & $36(21.8 \%)$ & $9(4.6 \%)$ & $4(2 \%)$ & $30(15.2 \%)$ \\
Colorectal & $58 / 187(31.0 \%)$ & $3(1.6 \%)$ & $45(24 \%)$ & $7(3.7 \%)$ & $2(1 \%)$ & $1(0.5 \%)$ \\
Neuroendocrine & $9 / 56(16.1 \%)$ & $0(0 \%)$ & $7(12.5 \%)$ & $0(0 \%)$ & $0(0 \%)$ & $2(3.6 \%)$ \\
Cholangiocarcinoma & $11 / 35(31.4 \%)$ & $1(2.9 \%)$ & $7(20 \%)$ & $0(0 \%)$ & $2(5.7 \%)$ & $1(2.9 \%)$ \\
Breast & $6 / 27(22.2 \%)$ & $0(0 \%)$ & $4(14.8 \%)$ & $1(3.7 \%)$ & $1(3.7 \%)$ & $0(0 \%)$ \\
Melanoma & $4 / 16(25 \%)$ & $0(0 \%)$ & $3(18.8 \%)$ & $0(0 \%)$ & $0(0 \%)$ & $1(6.3 \%)$ \\
Pancreatic & $5 / 16(31.2 \%)$ & $0(0 \%)$ & $3(6.3 \%)$ & $0(0 \%)$ & $0(0 \%)$ & $2(12.5 \%)$ \\
Esophageal & $2 / 7(28.6 \%)$ & $0(0 \%)$ & $2(28.6 \%)$ & $0(0 \%)$ & $0(0 \%)$ & $0(0 \%)$ \\
Other & $24 / 73(32.9 \%)$ & $0(0 \%)$ & $22(30.1 \%)$ & $0(0 \%)$ & $0(0 \%)$ & $2(2.7 \%)$ \\
Total & $205 / 614(33.4 \%)$ & $11(1.8 \%)$ & $129(21 \%)$ & $17(2.8 \%)$ & $9(1.5 \%)$ & $39(6.4 \%)$ \\
\hline
\end{tabular}

Chemo, systemic therapy; SBRT, stereotactic body radiation to hepatic malignancy; Arterial, embolization or chemoembolization. 


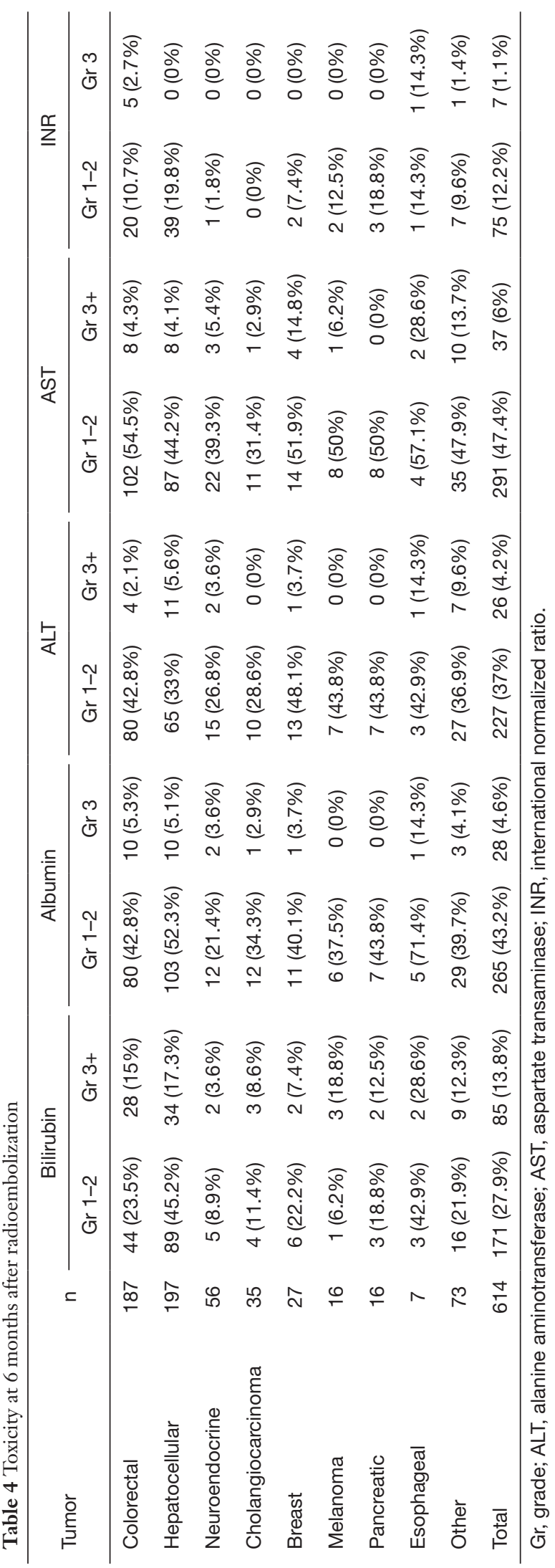

only in $2 \%$ of the remaining patients. Surgery, ablation and stereotactic radiation were each used in less than $3 \%$ of the cohort.

\section{Liver-function toxicity}

Table 4 demonstrates 6-month toxicity including the final labs for patients who dropped out. Grade 3 bilirubin toxicities were identified in $13.8 \%$ of patients. Both HCC $(17.3 \%)$ and colorectal carcinoma (15\%) had grade 3 toxicity rates that exceeded this value. Grade 3 albumin toxicities were $4.6 \%$, again with a greater incidence in HCC (5.3\%) and colorectal carcinoma (5.1\%). Grade 3 ALT and AST toxicities were $4.2 \%$ and $6 \%$, respectively. Grade 3 INR toxicity occurred in 7 patients (1.1\%) within the cohort. Five of these 7 (71.4\%) patients had colorectal carcinoma. The median absolute neutrophil count at 6 months was 4,300 (IQR: 3,100-6,530). Fourteen patients $(2.2 \%)$ developed an absolute neutrophil count $<1,500$ at 6 months. No patients had an absolute neutrophil count of 500 or less. There was no statistical difference in development of significant hepatic function toxicity based on the method of dosimetry.

\section{Other toxicity}

Other grade 3-5 toxicities are reported in Table 5. Thirtyone grade 3, nine grade 4 and 2 grade 5 events were reported. The most commonly reported toxicities were thrombocytopenia in 8 patients $(1.3 \%)$ and abdominal pain in 6 patients $(1.0 \%)$. Two patients $(0.3 \%)$ developed gastric ulcers.

\section{Response}

At 6 months, 499 (81.2\%) patients of the original group were available for imaging follow-up. Of these patients, 483 (78.7\%) had imaging within the defined response assessment time which used mRECIST or RECIST to determine response. The remaining patients $(n=16,2.6 \%)$ had positron emission scanning with or without computed tomography. Thirty-two $(6.6 \%)$ of the evaluable patients had complete response, 143 (29.6\%) had partial response, 150 (31.1\%) had stable disease and $158(32.5 \%)$ had progressive disease. One hundred seventy-five (36.2\%) of patients had an objective response, and $325(67.3 \%)$ of patients had disease control. Of the three most common tumor types, neuroendocrine tumor had the highest rates of objective 
Table 5 Other grade 3 and greater toxicities

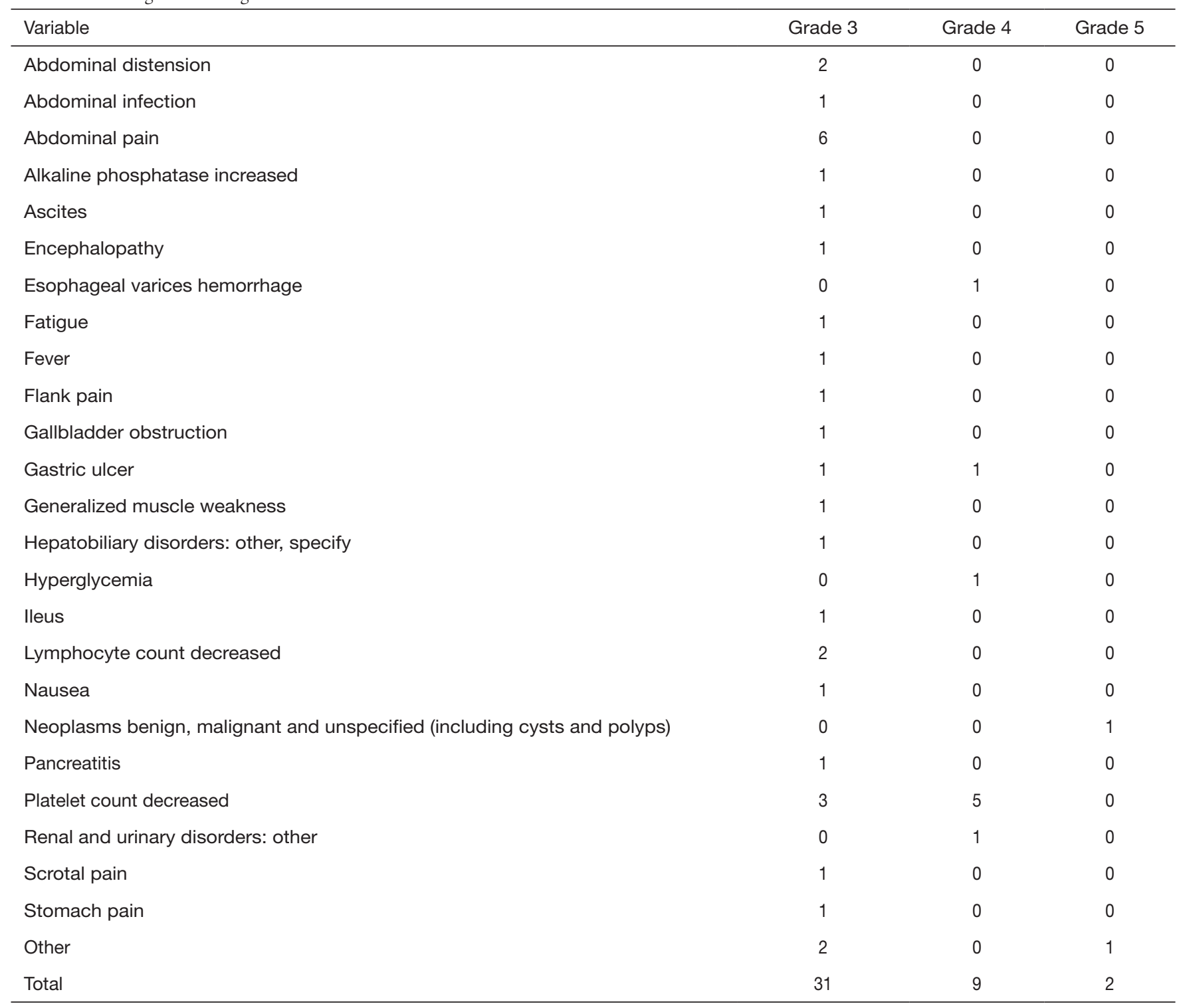

response (61.4\%) and disease control (93.2\%), while HCC had the greatest percentage of complete responses $(16.5 \%)$. One hundred forty-eight patients (93.6\%) with progressive disease developed hepatic progression. Of this group, 111 (75\%) progressed in the treatment zone while 37 (25\%) progressed outside the previously treated area. Additionally, 94 patients with progressive disease (59\%) developed new extrahepatic disease.

\section{Predictive factors of group toxicity}

Several factors predicted grade 3 or greater toxicity (Table 6) including increased age $(\mathrm{P}=0.046)$, male gender $(\mathrm{P}<0.001)$, primary liver cancer $(\mathrm{P}<0.001)$, metastatic tumor type $(\mathrm{P}<0.001)$, increased lung shunt percentage $(\mathrm{P}=0.004)$, increased delivered activity $(\mathrm{P}=0.04)$, bilobar compared with unilobar tumor $(\mathrm{P}=0.04)$, and baseline laboratory elevation compared with normal labs $(\mathrm{P}<0.001)$. Undergoing previous liver tumor intervention was associated with significant toxicity as well compared to treatment naïve patients $(\mathrm{P}=0.05)$. Previous surgery $(\mathrm{P}=0.01)$ specifically predicted an adverse outcome.

At linear regression, baseline liver function toxicity $(\mathrm{t}=16.6, \mathrm{P}<0.0001)$ and increased $\mathrm{BMI}(\mathrm{t}=2.79, \mathrm{P}=0.0056)$ 
Table 6 Association of baseline factors with hepatic toxicity. The number and percent of included data points are included in the right column. The Kruskal-Wallis Test ( 1 in final column) was used for continuous variables and Pearson Chi-squared test ( 2 in final column) for discrete variables

\begin{tabular}{|c|c|c|c|c|c|c|c|c|}
\hline Variable & $\mathrm{N}$ & $\begin{array}{c}\text { No toxicity, } \\
\mathrm{N}=337\end{array}$ & $\begin{array}{c}\text { Grade 1, } \\
\mathrm{N}=88\end{array}$ & $\begin{array}{c}\text { Grade 2, } \\
\mathrm{N}=83\end{array}$ & $\begin{array}{c}\text { Grade } 3, \\
N=66\end{array}$ & $\begin{array}{l}\text { Grade 4, } \\
\mathrm{N}=19\end{array}$ & $\begin{array}{l}\text { Combined, } \\
\mathrm{N}=614\end{array}$ & $P$ value/test \\
\hline Age & 614 & $64(55.0-70)$ & $64.5(60.0-70)$ & $67(59.5-71)$ & $62.0(56-67.8)$ & 59 (55.5-68) & $64(56.0-70)$ & $0.046^{\star} / 1$ \\
\hline Gender & 614 & & & & & & & $<0.001^{*} / 2$ \\
\hline Female & & $158(47 \%)$ & $18(20 \%)$ & $24(29 \%)$ & $23(35 \%)$ & $7(37 \%)$ & 230 & \\
\hline Race & 614 & & & & & & & $0.66 / 2$ \\
\hline White & & $264(78 \%)$ & $63(72 \%)$ & $72(87 \%)$ & $54(82 \%)$ & $18(95 \%)$ & $471(79 \%)$ & \\
\hline Black & & $39(12 \%)$ & $10(11 \%)$ & $7(8 \%)$ & $6(9 \%)$ & $0(0 \%)$ & $62(10 \%)$ & \\
\hline Other/unknown & & $17(5 \%)$ & $8(9 \%)$ & $3(3 \%)$ & $3(5 \%)$ & $1(5 \%)$ & $32(6 \%)$ & \\
\hline Ethnicity & 614 & & & & & & & $0.18 / 2$ \\
\hline Hispanic or Latino & & $19(6 \%)$ & $1(1 \%)$ & $3(4 \%)$ & $6(9 \%)$ & $2(11 \%)$ & $31(5 \%)$ & \\
\hline Non-Hispanic & & $298(88 \%)$ & $76(86 \%)$ & 75 (90\%) & $56(85 \%)$ & 17 (89\%) & $522(88 \%)$ & \\
\hline Other/unknown & & $20(6 \%)$ & $11(12 \%)$ & $5(6 \%)$ & $4(6 \%)$ & $0(0 \%)$ & $40(7 \%)$ & \\
\hline Tumor type & 614 & & & & & & & $<0.001 * / 2$ \\
\hline Primary & & $101(30 \%)$ & $56(64 \%)$ & $39(47 \%)$ & $33(50 \%)$ & $5(26 \%)$ & $234(39 \%)$ & \\
\hline All tumors & 614 & & & & & & & $<0.001 * / 2$ \\
\hline $\mathrm{HCC}$ & & $73(22 \%)$ & 52 (59\%) & $37(45 \%)$ & $29(44 \%)$ & $5(26 \%)$ & $196(33 \%)$ & \\
\hline Colorectal & & $107(32 \%)$ & $14(16 \%)$ & $30(36 \%)$ & $20(30 \%)$ & $8(42 \%)$ & $179(30 \%)$ & \\
\hline Neuroendocrine & & $46(14 \%)$ & $4(5 \%)$ & $1(1 \%)$ & $2(3 \%)$ & $0(0 \%)$ & $53(9 \%)$ & \\
\hline Cholangio & & $26(8 \%)$ & $3(3 \%)$ & $1(1 \%)$ & $3(5 \%)$ & $0(0 \%)$ & $33(6 \%)$ & \\
\hline Breast & & $18(5 \%)$ & $3(3 \%)$ & $3(4 \%)$ & $1(2 \%)$ & $1(5 \%)$ & $26(4 \%)$ & \\
\hline Melanoma & & $12(4 \%)$ & $1(1 \%)$ & $0(0 \%)$ & $1(2 \%)$ & $2(11 \%)$ & $16(3 \%)$ & \\
\hline Pancreas & & $8(2 \%)$ & $2(2 \%)$ & $1(1 \%)$ & $1(2 \%)$ & $1(5 \%)$ & $13(2 \%)$ & \\
\hline Esophageal & & $2(1 \%)$ & $1(1 \%)$ & $2(2 \%)$ & $2(3 \%)$ & $0(0 \%)$ & $7(1 \%)$ & \\
\hline Lung & & $5(1 \%)$ & $0(0 \%)$ & $1(1 \%)$ & $0(0 \%)$ & $0(0 \%)$ & $6(1 \%)$ & \\
\hline
\end{tabular}

Table 6 (continued) 
Table 6 (continued)

\begin{tabular}{|c|c|c|c|c|c|c|c|c|}
\hline Variable & $\mathrm{N}$ & $\begin{array}{c}\text { No toxicity, } \\
N=337\end{array}$ & $\begin{array}{c}\text { Grade 1, } \\
\mathrm{N}=88\end{array}$ & $\begin{array}{c}\text { Grade 2, } \\
\mathrm{N}=83\end{array}$ & $\begin{array}{c}\text { Grade } 3, \\
N=66\end{array}$ & $\begin{array}{c}\text { Grade 4, } \\
\mathrm{N}=19\end{array}$ & $\begin{array}{l}\text { Combined, } \\
\mathrm{N}=614\end{array}$ & $P$ value/test \\
\hline Other & & $40(12 \%)$ & $8(9 \%)$ & $7(8 \%)$ & $7(11 \%)$ & $0(0 \%)$ & $62(10 \%)$ & \\
\hline ECOG & 594 & & & & & & & $0.13 / 2$ \\
\hline 0 & & $152(47 \%)$ & $38(45 \%)$ & $44(54 \%)$ & $22(34 \%)$ & $6(35 \%)$ & $262(46 \%)$ & \\
\hline 3 & & $2(1 \%)$ & $3(4 \%)$ & $0(0 \%)$ & $0(0 \%)$ & $0(0 \%)$ & $5(1 \%)$ & \\
\hline 4 & & $1(<1 \%)$ & $0(0 \%)$ & $0(0 \%)$ & $1(2 \%)$ & $0(0 \%)$ & $2(<1 \%)$ & \\
\hline BMI & 609 & $27.6(23.8-32)$ & $\begin{array}{c}27.2(23.1- \\
30.1)\end{array}$ & $\begin{array}{c}27.3(23.4- \\
31.4)\end{array}$ & $\begin{array}{c}27.7(24.7- \\
31.4)\end{array}$ & $\begin{array}{c}28.5(25.1- \\
30.3)\end{array}$ & $27.6(23.0-31.6)$ & $0.78 / 1$ \\
\hline Patent & & $299(90 \%)$ & $74(86 \%)$ & 73 (89\%) & $55(85 \%)$ & $14(82 \%)$ & $515(89 \%)$ & \\
\hline Segmental thrombus & & $9(3 \%)$ & $4(5 \%)$ & $1(1 \%)$ & $1(2 \%)$ & $1(6 \%)$ & $16(3 \%)$ & \\
\hline Main thrombus & & $2(1 \%)$ & $3(3 \%)$ & $4(5 \%)$ & $2(3 \%)$ & $0(0 \%)$ & $11(2 \%)$ & \\
\hline Lobar thrombus & & $4(1 \%)$ & $2(2 \%)$ & $1(1 \%)$ & $2(3 \%)$ & $0(0 \%)$ & $9(2 \%)$ & \\
\hline $\begin{array}{l}\text { Cavernous } \\
\text { transformation }\end{array}$ & & $1(<1 \%)$ & $1(1 \%)$ & $0(0 \%)$ & $3(5 \%)$ & $1(6 \%)$ & $6(1 \%)$ & \\
\hline Tumor volume (\%) & 567 & $14.8 \%(5.5-30)$ & $10 \%(6.0-25)$ & $15 \%(6.5-25)$ & $20 \%(9.3-30)$ & $\begin{array}{c}21.1 \% \\
(9.9-30)\end{array}$ & $15 \%(6.9-30)$ & $0.27 / 1$ \\
\hline BSA & & $105(53 \%)$ & 35 (56\%) & $32(60 \%)$ & $16(59 \%)$ & $3(27 \%)$ & $191(54 \%)$ & \\
\hline Empiric & & $1(1 \%)$ & $2(3 \%)$ & $2(4 \%)$ & $0(0 \%)$ & $0(0 \%)$ & $5(1 \%)$ & \\
\hline Modified BSA & & $56(28 \%)$ & $15(24 \%)$ & $14(26 \%)$ & 9 (33\%) & $4(36 \%)$ & $98(28 \%)$ & \\
\hline Partition & & $15(8 \%)$ & $6(10 \%)$ & $2(4 \%)$ & $1(4 \%)$ & $2(18 \%)$ & $26(7 \%)$ & \\
\hline Other & & $21(11 \%)$ & $4(6 \%)$ & $3(6 \%)$ & $1(4 \%)$ & $2(18 \%)$ & $31(9 \%)$ & \\
\hline Infusion zone & 614 & & & & & & & $0.086 / 2$ \\
\hline Whole liver & & $147(44 \%)$ & $30(34 \%)$ & 29 (35\%) & 37 (56\%) & $11(58 \%)$ & $254(43 \%)$ & \\
\hline Right & & $132(39 \%)$ & $41(47 \%)$ & $40(48 \%)$ & $21(32 \%)$ & $6(32 \%)$ & $240(40 \%)$ & \\
\hline Left & & $40(12 \%)$ & $9(10 \%)$ & $10(12 \%)$ & $6(9 \%)$ & $2(11 \%)$ & $67(11 \%)$ & \\
\hline Segment & & $12(4 \%)$ & $7(8 \%)$ & $4(5 \%)$ & $0(0 \%)$ & $0(0 \%)$ & $23(4 \%)$ & \\
\hline Lobe + segment & & $6(1 \%)$ & $1(1 \%)$ & $0(0 \%)$ & $2(3 \%)$ & $0(0 \%)$ & $9(2 \%)$ & \\
\hline
\end{tabular}

Table 6 (continued) 
Table 6 (continued)

\begin{tabular}{|c|c|c|c|c|c|c|c|c|}
\hline Variable & $\mathrm{N}$ & $\begin{array}{l}\text { No toxicity, } \\
\quad \mathrm{N}=337\end{array}$ & $\begin{array}{l}\text { Grade 1, } \\
\qquad N=88\end{array}$ & $\begin{array}{l}\text { Grade 2, } \\
\qquad N=83\end{array}$ & $\begin{array}{c}\text { Grade } 3 \\
\mathrm{~N}=66\end{array}$ & $\begin{array}{l}\text { Grade 4, } \\
\mathrm{N}=19\end{array}$ & $\begin{array}{l}\text { Combined, } \\
\mathrm{N}=614\end{array}$ & $P$ value/test \\
\hline Baseline lab toxicity & 614 & & & & & & & $<0.001^{*} / 1$ \\
\hline Albumin & & $4.0(3.7-4.2)$ & $3.7(3.5-4)$ & $3.5(3.1-3.8)$ & $3.3(2.7-3.6)$ & & $3.4(3.8-4.1)$ & \\
\hline Bilirubin & & $0.5(0.4-0.7)$ & $0.9(0.6-1.2)$ & $1.0(0.6-1.3)$ & $0.8(0.5-1.1)$ & $0.8(0.6-1.2)$ & $0.7(0.5-0.9)$ & \\
\hline INR & & $1.1(1-1.2)$ & $1.2(1.1-1.3)$ & $1.3(1.2-1.4)$ & $1.1(1.0-1.2)$ & & $1.1(1.0-1.2)$ & \\
\hline MELD (HCC only) & 196 & $7(7.0-9)$ & $9(7.5-12)_{-}$ & $11(8.0-12)$ & $9(7.3-11)$ & $13(11-13.5)$ & $8.5(7.0-11)$ & $<0.001^{*} / 1$ \\
\hline Child Pugh (HCC only) & 173 & $5(5.0-6)$ & $6(5.0-7)$ & $7(6.0-7)$ & $6(5.3-7)$ & $7(6-7.5)$ & $6(5.0-7)$ & $<0.001^{*} / 1$ \\
\hline Stable disease & & $83(27 \%)$ & $20(25 \%)$ & $13(18 \%)$ & 24 (39\%) & 5 (33\%) & $145(27 \%)$ & \\
\hline Progressive disease & & $91(29 \%)$ & $18(23 \%)$ & 27 (38\%) & $14(23 \%)$ & $6(40 \%)$ & $156(29 \%)$ & \\
\hline Unevaluable & & $34(11 \%)$ & $11(14 \%)$ & $10(14 \%)$ & $10(16 \%)$ & $1(7 \%)$ & $66(12 \%)$ & \\
\hline Previous surgery & 575 & & & & & & & $0.01^{*} / 2$ \\
\hline Yes & & $40(12 \%)$ & $2(2 \%)$ & $5(6 \%)$ & $4(7 \%)$ & $4(24 \%)$ & $55(10 \%)$ & \\
\hline No & & 291 (88\%) & $86(98 \%)$ & 75 (94\%) & 55 (93\%) & $13(76 \%)$ & $536(90 \%)$ & \\
\hline Ablation & 584 & & & & & & & $0.11 / 2$ \\
\hline External radiation & 586 & & & & & & & $0.55 / 2$ \\
\hline Yes & & $23(7 \%)$ & $2(2 \%)$ & $4(5 \%)$ & $3(5 \%)$ & $1(5 \%)$ & $33(6 \%)$ & \\
\hline No & & $310(93 \%)$ & $85(98 \%)$ & $78(95 \%)$ & $62(95 \%)$ & $18(95 \%)$ & $553(94 \%)$ & \\
\hline Lines systemic therapy & 374 & $2[1-3]$ & $1[1-2]$ & $2[1-4]$ & $2[1-4]$ & & $2[1-3]$ & $0.4 / 2$ \\
\hline
\end{tabular}

Items including ranges represent the median with lower and upper quartiles in parentheses. The number of reported outcomes from the entire patient group are included in the second column. *, P<0.05. HCC, hepatocellular carcinoma; ECOG, Eastern Cooperative Oncology Group; BMI, body-mass index; ALT, alanine aminotransferase; AST, aspartate transaminase; INR, international normalized ratio; Cholangio, cholangiocarcinoma; MELD, model for end-stage liver disease. 
predicted post-therapy toxicity for albumin (Table 7). Baseline liver function elevation $(t=3.7, P=0.0002)$ and whole liver therapy $(\mathrm{t}=2, \mathrm{P}=0.05)$ predicted grade 3 toxicity for bilirubin (Table 8). The significant linear regression results for ALT, AST and INR are summarized in Table 9. Notably, baseline liver function toxicity was a strong predictor of grade 3 toxicity for ALT and AST.

Predictive Factors for the Most Common Tumors: The regression model fit for HCC (Table 10) and colorectal cancer (Table 11). Factors predicting any Grade 3 toxicity for HCC included presence of extrahepatic disease at treatment with TARE. Numerous factors predicted Grade 3 toxicity for colorectal carcinoma, including previous arterial intervention, lower prescribed activity, white race, increased $\mathrm{BMI}$, presence of baseline toxicity, whole-liver therapy, and lower tumor volume.

\section{Discussion}

The current study found that abnormal baseline function tests were the single strongest predictor of grade 3 toxicity 6 months following radioembolization. This factor correlated with grade 3 elevations of bilirubin $(n=85,13.8 \%)$ and albumin $(n=28,4.6 \%)$. Other factors, such as elevated BMI, tumor volume, or whole-liver therapy predicted post-treatment toxicity of individual lab values. However, baseline liver toxicity applied universally across this patient sample outside of INR, which had the lowest incidence of grade 3 toxicity. This group was heavily pre-treated prior to radioembolization: $40.4 \%$ of the patients received 2 or more lines of systemic therapy, $9.6 \%$ underwent resection, and $29.5 \%$ had locoregional therapies including embolization, thermal ablation or SBRT. Most patients were treated as salvage candidates: $37.6 \%$ of HCC patients had previous arterial therapy/ablation and $28.3 \%$ had gotten systemic therapy, while $32.6 \%$ of colorectal and $25 \%$ of neuroendocrine patients had received 3 or more lines of therapy at the time of referral. The lack of additional therapy in two-thirds of the patient group reinforces the end-stage nature of the treatment group, particularly given the use of maintenance systemic agents for the majority of disease types outside of neuroendocrine tumor and HCC. Despite the extensive pre-treatment and salvage status, we achieved a $36 \%$ objective response and $67 \%$ disease control rate.

Both colorectal carcinoma and HCC had Grade 3 toxicity rates above the group mean for several lab values. This finding reflects baseline hepatotoxicity from previous chemotherapy used for colorectal carcinoma and underlying cirrhosis in HCC (18-20). The $1.1 \%$ incidence of likely radiation-induced liver disease (7/614 patients) is slightly lower than the $4 \%$ rate described by Kennedy et al. (13). The data in this patient group also reinforces findings from smaller studies including that patients with lower tumor burden have an increased risk of toxicity due to a greater proportion of activity delivery to uninvolved liver $(21,22)$. Additionally, patients who have undergone previous resection are at increased risk of toxicity as dose calculations do not accommodate for smaller organs (1). Patients with colorectal cancer had the highest resection rate in our cohort.

Grade 3 bilirubin toxicities following radioembolization range from $5-13 \%$ for breast, hepatocellular and colorectal carcinoma and up to $21 \%$ following TACE (3,22-25). Hypoalbuminemia outcomes are reported as albumin toxicity or ascites development in different studies. Reported rates of grade 3 albumin toxicity range from 5-8\% for radioembolization and $0-19 \%$ for TACE for HCC $(3,22,23)$. Increased ascites following radioembolization has been reported in $5.1 \%$ of colorectal cancer patients and $29 \%$ of breast cancer patients following radioembolization (24-26). While not all systemic therapies are hepatotoxic, it is important for the treating interventional radiologist to recognize the increased risk when patients have received such agents in combination with baseline hepatic dysfunction. Pre-existing hepatic toxicity can be exacerbated after bilobar treatments.

\section{HCC specific outcomes}

The 197 patients with HCC had a broad range of treatment prior to TARE, including embolization in $50(25.4 \%)$, ablation in $24(12.2 \%)$, and systemic therapy in $28(14.2 \%)$ patients. Previous resection was performed in $8(4.1 \%)$ patients. Twenty-eight (14\%) of patients had some degree of portal vein thrombosis including $10(5 \%)$ with main portal vein occlusion. In this cohort, patients with primary tumors had greater baseline lab abnormalities. Seventeen patients $(9 \%)$ were treated with segmental TARE, with the remaining getting whole liver $(\mathrm{n}=51,26 \%)$ or lobar $(\mathrm{n}=129$, $65 \%$ ) infusion. The toxicity rate increased with elevated MELD and Child-Pugh scores. Significant bilirubin and albumin toxicity developed in $34(17.3 \%)$ and $10(5.1 \%)$ of patients, respectively. In the whole group linear regression, Bilirubin and albumin toxicity was also associated with bilobar therapy $(\mathrm{P}=0.046)$ and elevated $\mathrm{BMI}(\mathrm{P}=0.0056)$. 
Table 7 Linear regression of predicting demographics for grade 3 albumin toxicity

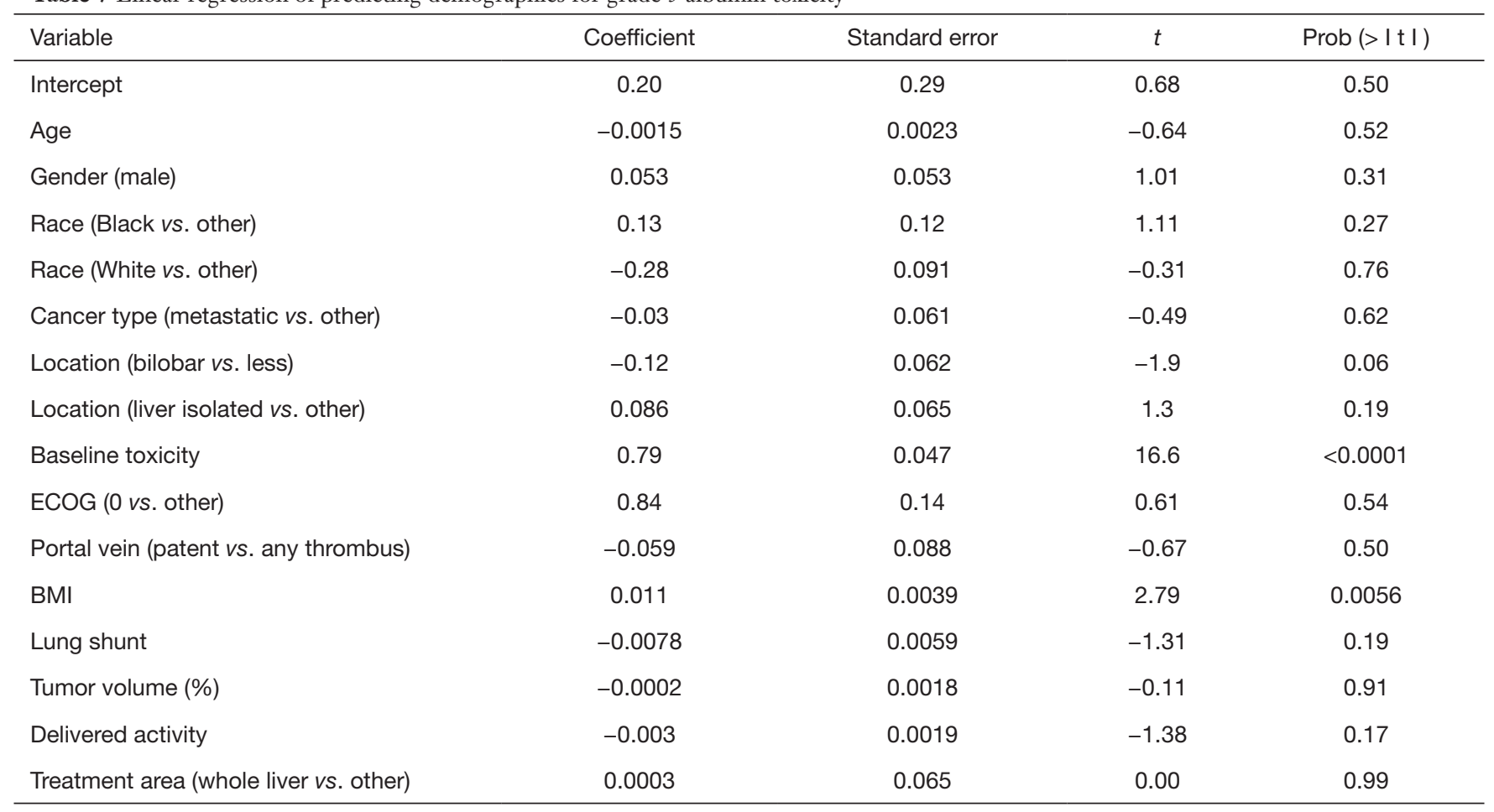

ECOG, Eastern Cooperative Oncology Group; BMI, body-mass index.

Table 8 Linear regression of predicting demographics for grade 3 bilirubin toxicity

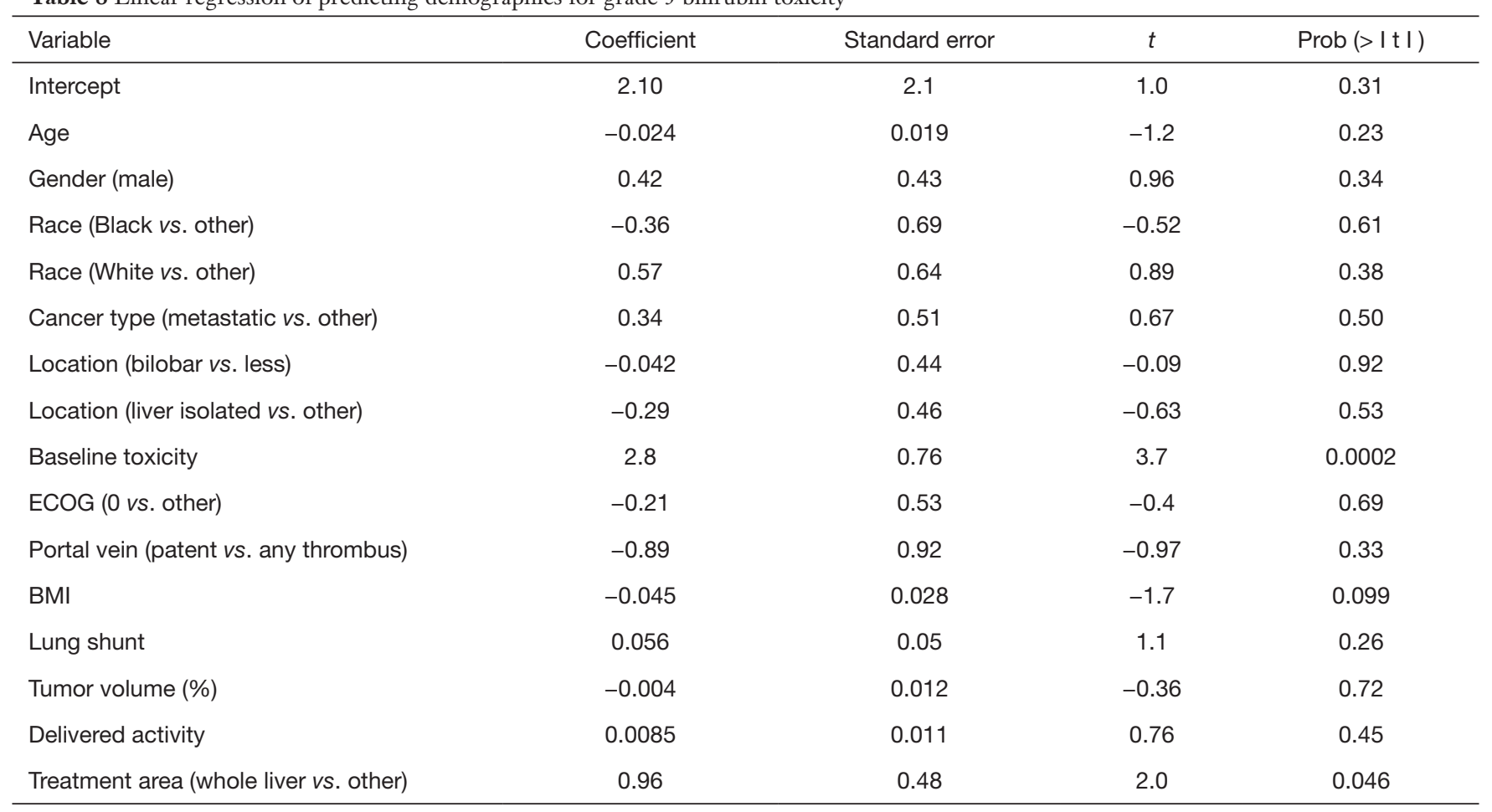

ECOG, Eastern Cooperative Oncology Group; BMI, body-mass index. 
Table 9 Summary of statistically significant findings for Linear Regression of ALT, AST and INR

\begin{tabular}{|c|c|c|c|c|}
\hline Value & Co-efficient & $\begin{array}{c}\text { Standard } \\
\text { error }\end{array}$ & $t$ & $\begin{array}{c}\text { Probability } \\
(>|\mathrm{t}|)\end{array}$ \\
\hline \multicolumn{5}{|l|}{ ALT } \\
\hline Age & -0.96 & 0.40 & -2.4 & 0.017 \\
\hline $\begin{array}{l}\text { Race (White vs. } \\
\text { other) }\end{array}$ & 26.8 & 10.4 & 2.58 & 0.01 \\
\hline Baseline toxicity & 0.74 & 0.22 & 3.41 & 0.0007 \\
\hline Tumor volume & -0.74 & 0.35 & -2.12 & 0.035 \\
\hline \multicolumn{5}{|l|}{ AST } \\
\hline White & 43.93 & 16.34 & 2.69 & 0.007 \\
\hline Baseline toxicity & 1.37 & 0.36 & 3.78 & 0.0002 \\
\hline \multicolumn{5}{|l|}{ INR } \\
\hline Tumor volume & -0.022 & 0.01 & -2.14 & 0.03 \\
\hline ECOG (>1 vs. 0) & 0.47 & 0.22 & 2.17 & 0.03 \\
\hline Portal vein patent & -0.9 & 0.39 & -2.32 & 0.02 \\
\hline
\end{tabular}

ALT, alanine aminotransferase; AST, aspartate transaminase; INR, international normalized ratio; ECOG, Eastern Cooperative Oncology Group.
In the HCC specific logistic regression, the presence of extra-hepatic disease predicted toxicity. Senthilnathan et al. reported a $28 \%$ incidence in the development of extrahepatic disease following locoregional therapy (27). Extrahepatic disease was most common patients with aggressive tumors. The subgroup of patients treated in the current study likely had similar tumor biology which could have contributed to post-treatment toxicity.

Salem et al. have described selection bias in HCC treatment with operators preferentially choosing radioembolization over chemoembolization to treat patients with advanced HCC (28). Twenty-seven percent of their group received systemic therapy, which is indicated for advanced HCC (29). In the current group, $14.3 \%$ of HCC patients also received second and third-line systemic regimens and $38.6 \%$ also underwent locoregional therapy.

Treatment naive patients have lower toxicity rates in radioembolization trials. First-line TARE in patients with intermediate to advanced HCC in the SIRveNIB and SARAH trials had a $3 \%$ grade 3 hyperbilirubinemia risk, $0.8 \%$ risk of grade 3 albumin toxicity and a $4 \%$ risk of grade 3 ascites $(30,31)$. Conversely, combination of TARE with sorafenib increases toxicity rates. Ricke et al. reported

Table 10 Logistic regression of factors associated with likelihood of any grade 3 toxicity for hepatocellular carcinoma

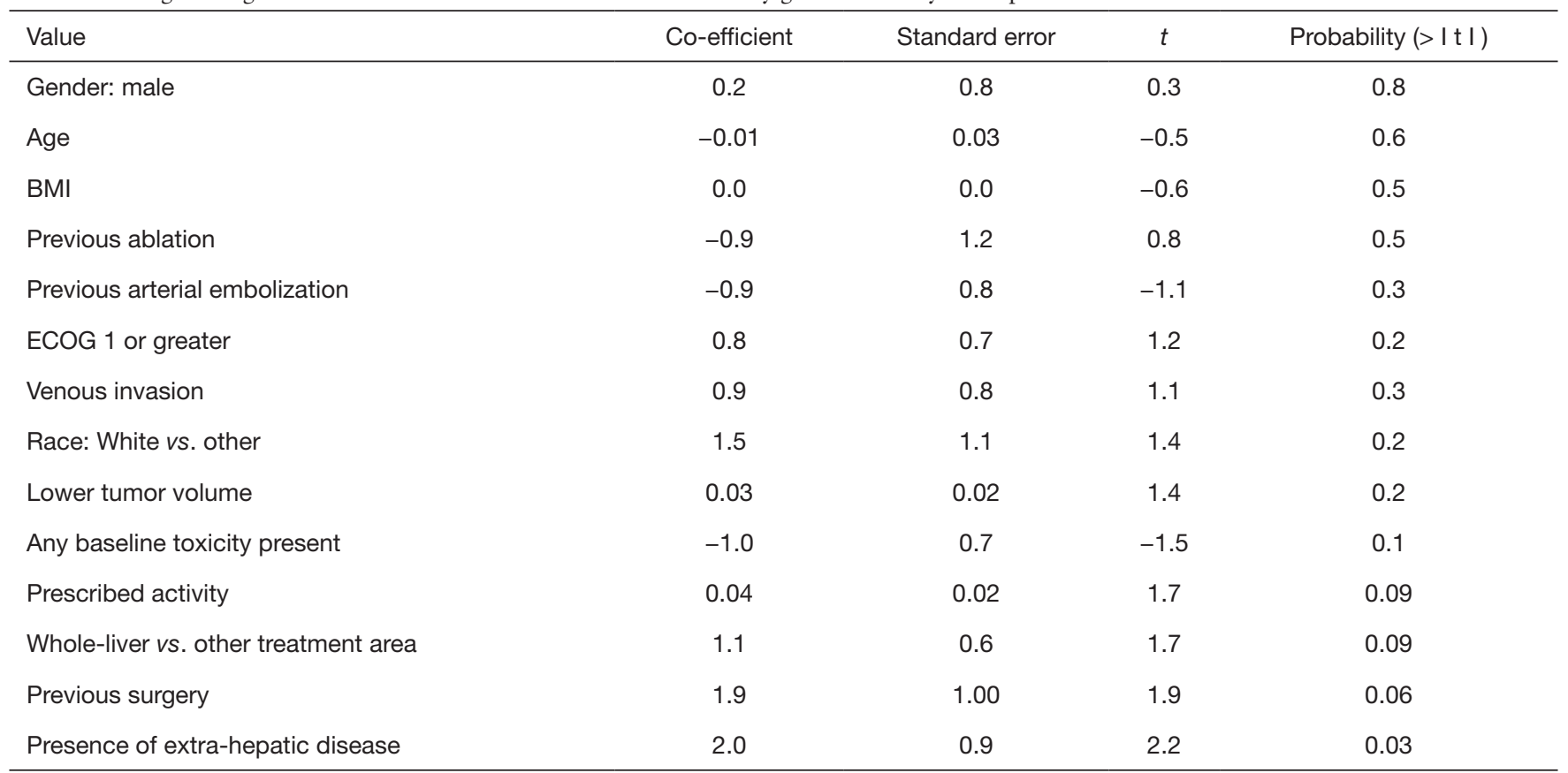

BMI, body-mass index; ECOG, Eastern Cooperative Oncology Group. 
Table 11 Logistic regression of factors associated with likelihood of any grade 3 toxicity for colorectal carcinoma

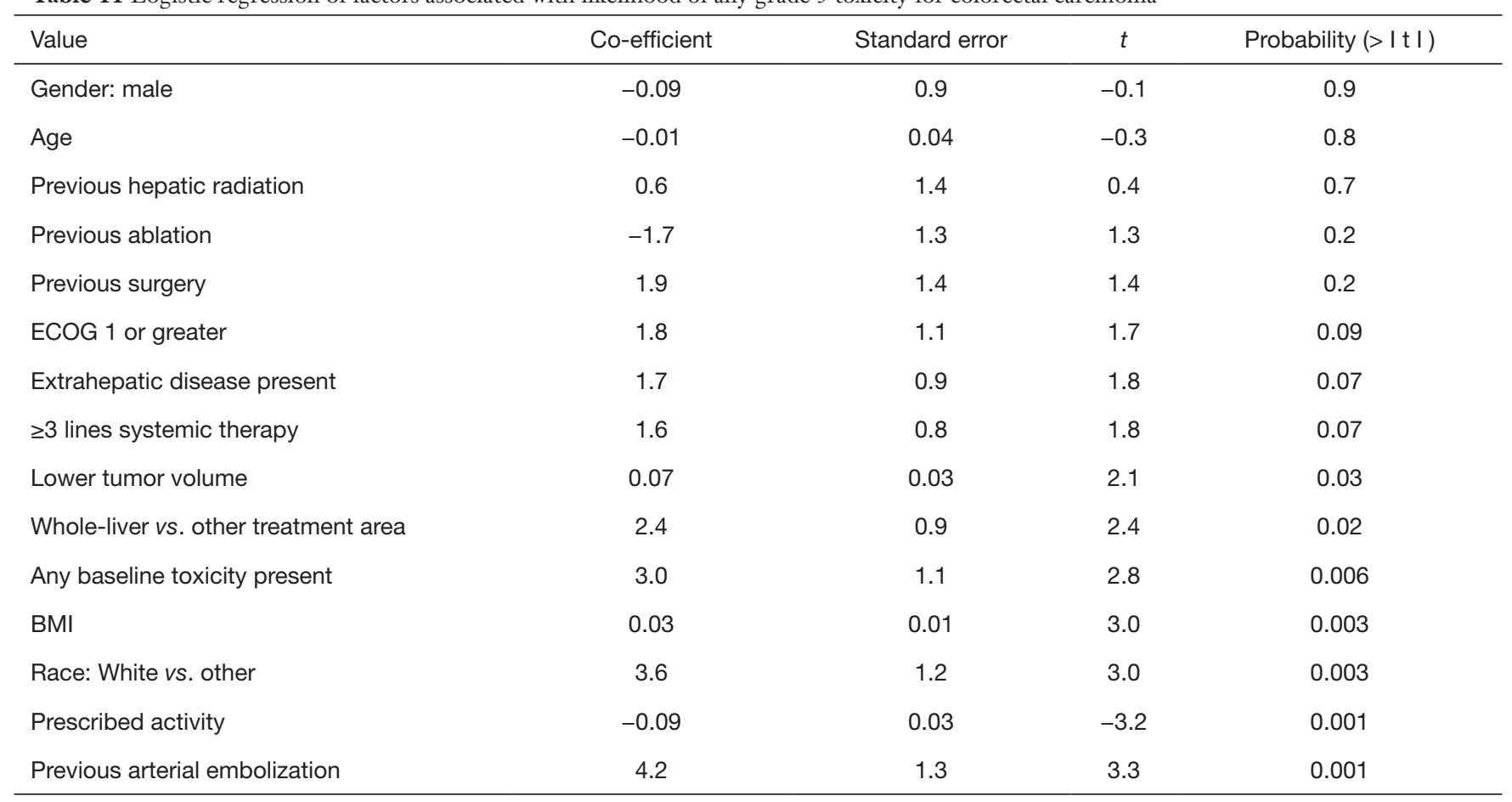

BMI, body-mass index; ECOG, Eastern Cooperative Oncology Group.

an increase of grade 3 hyperbilirubinemia from $4.4 \%$ with sorafenib alone to $14.5 \%$ (8). In a retrospective review of 26 patients, Zhan et al. reported 2 patients (7.7\%) with grade 3 bilirubin toxicity and 4 (15.4\%) with grade 3 albumin/ascites toxicity when combining radioembolization with either nivolumab or combined ipilimumab/nivolumab (15). Their group included intermediate and advanced HCC and half the patients had undergone previous intervention. Based on the results of this group, future trials in HCC should focus on treatment naive patients with normal baseline lab values, especially in light of the increasing incidence of nonalcoholic steatohepatitis and if bilobar treatment is being considered (32). As prospective trials represent an idealized patient scenario, recruitment would likely mirror that of Llovet et al. where 903 patients were screened to recruit 112 patients when comparing chemoembolization, embolization and best supportive care for HCC (33).

\section{Colorectal carcinoma}

The 188 colorectal carcinoma patients had the highest resection rate in this cohort $(\mathrm{n}=29,15.5 \%)$ and the majority of patients had received $2(n=43,23 \%)$ or 3 or more $(61$, $32.6 \%)$ lines of chemotherapy. A number of patients were treated with loco-regional therapy including ablation $(\mathrm{n}=26,13.9 \%)$, SBRT $(\mathrm{n}=12,6.4 \%)$ and embolization $(\mathrm{n}=14,7.5 \%)$. There were no patients with portal vein thrombosis in this group. Significant bilirubin and albumin toxicity developed in $28(15 \%)$ and $10(5.3 \%)$, respectively. Colorectal carcinoma was also the most common group to develop Grade 3 INR toxicity $(n=5,2.7 \%)$. In the colorectal carcinoma specific regression, baseline hepatic toxicity, previous arterial embolization, increased bodymass index, whole-liver treatment, and lower tumor volume all predicted an increased risk of Grade 3 or greater toxicity. Of note, 3 or more lines of systemic therapy did not reach the threshold as a risk for toxicity.

Toxicity following TARE increases with more chemotherapy, especially given the hepatotoxicities associated with oxaliplatin and irinotecan $(16,17)$. The FOXFIRE global study reported a $1 \%$ grade 3 toxicity both for bilirubin and ascites when using TARE firstline combined with oxaliplatin-based chemotherapy for colorectal cancer (9). While radioembolization was well-tolerated, the failure to increase overall survival means future trials will focus on radioembolization treatment beyond first-line therapy. Beyond second-line systemic therapy, level one evidence exists for standalone 
radioembolization to improve survival compared to best supportive care (34). Overall survival with systemic salvage regimens or TARE averages under one year $(35,36)$. Over half the patients in this group required bilobar therapy so improved outcomes combining TARE and biologic, immune-, or systemic therapy should focus on patients with normal baseline liver functions (30-32).

\section{Neuroendocrine tumor}

The 56 patients with neuroendocrine tumor received a variety of pre-TARE treatments including resection $(n=8$, $14.3 \%)$, embolization ( $n=9,16.1 \%)$, ablation $(n=4,7.1 \%)$ and SBRT ( $\mathrm{n}=3,5.4 \%)$. Additionally, 2 or 3 lines of therapy were given in $9(16.1 \%)$ and $14(26 \%)$ of patients. This group developed a lower rate of bilirubin and toxicity compared to HCC and colorectal cancer patients $(\mathrm{n}=2$, $3.6 \%$ for both levels). The more moderate toxicity rates reflect the absence of baseline liver damage from cirrhosis or chemotherapy-associated toxicity.

Neuroendocrine tumors are undergoing an evolution in care. Approval of peptide receptor radionuclide therapy (PRRT) has led to rapid clinical integration (37). Also, since 2017, separate investigations reported a low, but demonstrable rate of chronic hepatotoxicity in neuroendocrine patients surviving several years after radioembolization $(10,11)$. Given the availability of multiple radioactive agents to treat a group of patients with potentially prolonged survival, especially those with low-grade tumors, groups such as the North American Neuroendocrine Tumor Society are advocating caution in device selection when arterial therapy is being considered in potential future candidates for PRRT (12). Although evidence exists that patients can safely receive both therapies, this topic will require further study (14). Given the association of whole liver TARE with a low, but notable incidence of chronic toxicity, future research should focus on identifying tumor volumes/dosimetry to minimize liver toxicity $(10,11)$.

As RESIN is an observational study, there is an inherent limitation related to potential selection bias and lack of a control arm. Objective measures of hepatic dysfunction were used to avoid variability in assessment of encephalopathy and ascites. Additionally, the mix of tumor types limits some conclusions that be made regarding dosimetry guidelines moving forward. We did not calculate tumor or pulmonary dosimetry. However, the provided activity measurements are within the Society of Interventional Radiology reporting guidelines. Sites entered data at self-monitored time points, resulting in less than $100 \%$ entry. As the data in the registry continues to mature, more focused reviews of specific tumor types will be performed. This group suffers from lead-time bias related to multiple previous treatments and the toxicity rates are almost certainly higher than in more treatment naïve patients. However, the multicenter design also reinforces that this referral pattern is common across the United States.

\section{Conclusions}

In summary, the current study demonstrates that radioembolization was well-tolerated clinically in a heavily pretreated group of patients. For primary hepatic malignancy, future clinical trials would ideally include treatment naïve patients. In patients with metastatic disease, bilobar therapy will more commonly be required. Future studies should focus primarily on baseline liver function to optimize recruitment and minimize toxicity, particularly if bilobar treatment is planned in the setting of limited tumor volume.

\section{Acknowledgments}

The authors would like to acknowledge Zachary Collins, MD; Suvranu Ganguli, MD; Christopher Grilli, DO;Shannon Peck, MD; Nabeel Akhter, MD; Charles Hennemeyer, MD; Nicholas Fidelman, MD; Marc Matrana, MD; Alexander Kim, MD; Cliff Davis, MD; Navesh Sharma, DO, PhD; Khashayar Farsad, MD, PhD; Nima Kokabi, MD; Prasoon Mohan, MD; Charles Martin, MD; Jon Davidson, MD; Gary Siskin, MD; Islam Shahin, MD; Michael Petroziello, MD; Ricky Tong, MD; James Meek, MD; Anthony Brown, MD; Robert K. Ryu, MD; Ahmed Kamel Abdel Aal, MD; and Mark Westcott, MD Funding: This work was supported by Sirtex Medical.

\section{Footnote}

Reporting Checklist: We present the study in accordance with the STROBE reporting checklist. Available at http://dx.doi. org/10.21037/jgo-20-346

Data Sharing Statement: Available at http://dx.doi. org/10.21037/jgo-20-346

Conflicts of Interest: All authors have completed the ICMJE 
uniform disclosure form (Available at http://dx.doi. org/10.21037/jgo-20-346). DB receives research support from Sirtex Medical and consults for Bard and Boston Scientific outside the submitted work. JB reports personal fees from Sirtex Medical outside the submitted work. EW is a proctor for Sirtex Medical and speaker/educator for Terumo outside the submitted work. KV is a consultant Merit, Siemens, Sirtex Medical and Terumo outside the submitted work. DDS is a consultant for Medtronic and Sirtex Medical outside the submitted work. DYS is a consultant for Sirtex, Boston Scientific/BTG/Nordion, and Terumo/Quirem outside the submitted work. JG reports grants from Sirtex, during the conduct of the study. RG reports consulting and proctor fees from Sirtex, during the conduct of the study outside of the submitted work. AK has provided a webinar for Sirtex Medical and his institution has provided consulting for Sirtex Medical, outside the submitted work. The other authors have no conflicts of interest to declare.

Ethical Statement: The authors are accountable for all aspects of the work in ensuring that questions related to the accuracy or integrity of any part of the work are appropriately investigated and resolved. This study (GI 1523) was approved by the institutional review board at Vanderbilt University Medical Center (IRB \#150407) and at the other sites. Informed consent was obtained from all patients at each center. The study was performed in keeping with the Declaration of Helsinki (as revised in 2013).

Open Access Statement: This is an Open Access article distributed in accordance with the Creative Commons Attribution-NonCommercial-NoDerivs 4.0 International License (CC BY-NC-ND 4.0), which permits the noncommercial replication and distribution of the article with the strict proviso that no changes or edits are made and the original work is properly cited (including links to both the formal publication through the relevant DOI and the license). See: https://creativecommons.org/licenses/by-nc-nd/4.0/.

\section{References}

1. Samim M, van Veenendaal LM, Braat MNGJA, et al. Recommendations for radioembolisation after liver surgery using yttrium-90 resin microspheres based on a survey of an international expert panel. Eur Radiol 2017;27:4923-30.

2. Kennedy A, Brown DB, Feilchenfeldt J, et al. Safety of selective internal radiation therapy (SIRT) with yttrium-90 microspheres combined with systemic anticancer agents: Expert consensus. J Gastrointest Oncol 2017;8:1079-99.

3. Salem R, Gabr A, Riaz A, et al. Institutional Decision to Adopt Y90 as Primary Treatment for Hepatocellular Carcinoma Informed by a 1,000-Patient 15 -Year Experience. Hepatology 2018;68:1429-40.

4. Shah MH, Goldner WS, Halfdanarson TR, et al. NCCN Guidelines Insights: Neuroendocrine and Adrenal Tumors, Version 2.2018. J Natl Compr Canc Netw 2018;16:693-702.

5. Heimbach JK, Kulik LM, Finn RS, et al. AASLD Guidelines for the Treatment of Hepatocellular Carcinoma. Hepatology 2018;67:358-80.

6. Benson AB, Venook AP, Al-Hawary MM, et al. NCCN Guidelines Insights: Colon Cancer, Version 2.2018. J Natl Compr Canc Netw 2018;16:359-69.

7. Benson AB, D'Angelica MI, Abbott DE, et al. Guidelines Insights: Hepatobiliary cancers, version 2.2019. J Natl Compr Canc Netw 2019;17:302-10.

8. Ricke J, Klümpen HJ, Amthauer H, et al. Impact of combined selective internal radiation therapy and sorafenib on survival in advanced hepatocellular carcinoma. J Hepatol 2019;71:1164-74.

9. Wasan HS, Gibbs P, Sharma N, et al. First-line selective internal radiotherapy plus chemotherapy versus chemotherapy alone in patients with liver metastases from colorectal cancer (FOXFIRE, SIRFLOX, and FOXFIREGlobal): a combined analysis of three multicentre, randomised, phase 3 trials. Lancet Oncol 2017;18:1159-71.

10. Su YK, Mackey RV, Riaz A, et al. Long-Term Hepatotoxicity of Yttrium-90 Radioembolization as Treatment of Metastatic Neuroendocrine Tumor to the Liver. J Vasc Interv Radiol 2017;28:1520-6.

11. Tomozawa Y, Jahangiri Y, Pathak P, et al. LongTerm Toxicity after Transarterial Radioembolization with Yttrium-90 Using Resin Microspheres for Neuroendocrine Tumor Liver Metastases. J Vasc Interv Radiol 2018;29:858-65.

12. Strosberg JR, Halfdanarson TR, Bellizzi AM, et al. The north American neuroendocrine tumor society consensus guidelines for surveillance and medical management of midgut neuroendocrine tumors. Pancreas 2017;46:707-14.

13. Kennedy AS, McNeillie P, Dezarn WA, et al. Treatment Parameters and Outcome in 680 Treatments of Internal Radiation With Resin 90Y-Microspheres for Unresectable Hepatic Tumors. Int J Radiat Oncol Biol Phys 2009;74:1494-500.

14. Braat AJAT, Ahmadzadehfar H, Kappadath SC, et al. 
Radioembolization with 90Y Resin Microspheres of Neuroendocrine Liver Metastases After Initial Peptide Receptor Radionuclide Therapy. Cardiovasc Intervent Radiol 2020;43:246-53.

15. Zhan C, Ruohoniemi D, Shanbhogue KP, et al. Safety of Combined Yttrium-90 Radioembolization and Immune Checkpoint Inhibitor Immunotherapy for Hepatocellular Carcinoma. J Vasc Interv Radiol 2020;31:25-34.

16. Currie BM, Hoteit MA, Ben-Josef E, et al. Radioembolization-Induced Chronic Hepatotoxicity: A Single-Center Cohort Analysis. J Vasc Interv Radiol 2019;30:1915-23.

17. Padia SA, Lewandowski RJ, Johnson GE, et al. Radioembolization of Hepatic Malignancies: Background, Quality Improvement Guidelines, and Future Directions. J Vasc Interv Radiol 2017;28:1-15.

18. Zhao J, van Mierlo KMC, Gómez-Ramírez J, et al. Systematic review of the influence of chemotherapyassociated liver injury on outcome after partial hepatectomy for colorectal liver metastases. Br J Surg 2017;104:990-1002.

19. Zhao J, Sawo P, Rensen SS, et al. Impact of chemotherapyassociated liver injury on tumour regression grade and survival in patients with colorectal liver metastases. HPB 2018;20:147-54.

20. Kothary N, Weintraub JL, Susman J, et al. Transarterial Chemoembolization for Primary Hepatocellular Carcinoma in Patients at High Risk. J Vasc Interv Radiol 2007;18:1517-26.

21. Cremonesi M, Chiesa C, Strigari L, et al. Radioembolization of hepatic lesions from a radiobiology and dosimetric perspective. Front Oncol 2014;4:210.

22. Hickey R, Lewandowski RJ, Prudhomme T, et al. 90Y radioembolization of colorectal hepatic metastases using glass microspheres: Safety and survival outcomes from a 531-patient multicenter study. J Nucl Med 2016;57:665-71.

23. Mouli SK, Hickey R, Thornburg B, et al. Single- versus Triple-Drug Chemoembolization for Hepatocellular Carcinoma: Comparing Outcomes by Toxicity, Imaging Response, and Survival. J Vasc Interv Radiol 2016;27:1279-87.

24. Fendler WP, Lechner H, Todica A, et al. Safety, efficacy, and prognostic factors after radioembolization of hepatic metastases from breast cancer: A large single-center experience in 81 patients. J Nucl Med 2016;57:517-23.

25. Kennedy AS, Ball D, Cohen SJ, et al. Multicenter evaluation of the safety and efficacy of radioembolization in patients with unresectable colorectal liver metastases selected as candidates for $90 \mathrm{Y}$ resin microspheres. J Gastrointest Oncol 2015;6:134-42.

26. Sangro B, Gil-Alzugaray B, Rodriguez J, et al. Liver disease induced by radioembolization of liver tumors: Description and possible risk factors. Cancer 2008;112:1538-46.

27. Senthilnathan S, Memon K, Lewandowski RJ, et al. Extrahepatic metastases occur in a minority of hepatocellular carcinoma patients treated with locoregional therapies: Analyzing patterns of progression in 285 patients. Hepatology 2012;55:1432-42.

28. Salem R, Gilbertsen M, Butt Z, et al. Increased quality of life among hepatocellular carcinoma patients treated with radioembolization, compared with chemoembolization. Clin Gastroenterol Hepatol 2013;11:1358-65.e1.

29. Forner A, Reig M, Bruix J. Hepatocellular carcinoma. Lancet 2018;391:1301-14.

30. Chow PKH, Gandhi M, Tan S-B, et al. SIRveNIB: Selective Internal Radiation Therapy Versus Sorafenib in Asia-Pacific Patients With Hepatocellular Carcinoma. J Clin Oncol 2018;36:1913-21.

31. Vilgrain V, Pereira H, Assenat E, et al. Efficacy and safety of selective internal radiotherapy with yttrium-90 resin microspheres compared with sorafenib in locally advanced and inoperable hepatocellular carcinoma (SARAH): an open-label randomised controlled phase 3 trial. Lancet Oncol 2017;18:1624-36.

32. Loomba R, Lim JK, Patton H, et al. AGA Clinical Practice Update on Screening and Surveillance for Hepatocellular Carcinoma in Patients With Nonalcoholic Fatty Liver Disease: Expert Review. Gastroenterology 2020;158:1822-30.

33. Llovet JM, Real MI, Montaña X, et al. Arterial embolisation or chemoembolisation versus symptomatic treatment in patients with unresectable hepatocellular carcinoma: A randomised controlled trial. Lancet 2002;359:1734-9.

34. Seidensticker R, Denecke T, Kraus P, et al. Matched-pair comparison of radioembolization plus best supportive care versus best supportive care alone for chemotherapy refractory liver-dominant colorectal metastases. Cardiovasc Intervent Radiol 2012;35:1066-73.

35. Bester L, Meteling B, Pocock N, et al. Radioembolization versus standard care of hepatic metastases: Comparative retrospective cohort study of survival outcomes and adverse events in salvage patients. J Vasc Interv Radiol 2012;23:96-105. 
36. van Hazel GA, Pavlakis N, Goldstein D, et al. Treatment of fluorouracil-refractory patients with liver metastases from colorectal cancer by using yttrium-90 resin microspheres plus concomitant systemic irinotecan chemotherapy. J Clin Oncol 2009;27:4089-95.

37. Strosberg J, El-Haddad G, Wolin E, et al. Phase 3 trial of 177lu-dotatate for midgut neuroendocrine tumors. N Engl J Med 2017;376:125-35.

Cite this article as: Brown D, Krebs H, Brower J, O'Hara R, Wang E, Vaheesan K, Du L, Matsuoka L, D’Souza D, Sze DY, Golzarian J, Gandhi R, Kennedy A. Incidence and risk factors for sustained hepatic function toxicity 6 months after radioembolization: analysis of the radiation-emitting sir-spheres in non-resectable liver tumor (RESIN) registry. J Gastrointest Oncol 2021;12(2):639-657. doi: 10.21037/jgo-20-346 